\title{
A case of fatal acute hemorrhagic leukoencephalitis associated with severe acute respiratory syndrome-coronavirus- 2 infection
}

\author{
Rahul Jain ${ }^{1}$, Rishu Garg ${ }^{2}$, Ajoy Sodani ${ }^{3}$, Dinesh Chowksey ${ }^{1}$ \\ From ${ }^{1}$ Associate Professor, ${ }^{2}$ Senior Resident, ${ }^{3}$ Professor, Department of Neurology, Sri Aurobindo Institute of Medical Sciences Medical College, Indor, \\ Madhya Pradesh, India
}

$\mathrm{C}$

oronavirus (CoV) diseases (COVID)-19 is predominantly a respiratory virus, started with an outbreak in December 2019 and quickly grown into a global pandemic. Earlier respiratory symptoms were considered the initial symptoms but as reported by previous studies, neurological symptoms are also the cardinal initial manifestation of COVID-19. ${ }^{[1]}$ There is mounting evidence of neurological manifestations (ischemic and hemorrhagic strokes, Guillain-Barre syndrome, and leukoencephalopathies) that have been reported from different parts of the world ranging from benign symptoms to altered mental status and seizures. Still, there is relatively limited data regarding the neuroimaging complications of COVID-19. Here, we report a case of acute fatal leukoencephalitis in a patient with severe acute respiratory syndrome-CoV-2 (SARS-CoV-2), and imaging features are discussed.

A 67-years-old male was admitted with complaints of shortness of breath and fever for 5 days and diagnosed as SARS-CoV-2 positive on the reverse transcription-polymerase chain reaction test. On admission, the patient was febrile (100 F) with blood pressure (BP) of 110/70 $\mathrm{mmHg}$, pulse rate of 84/
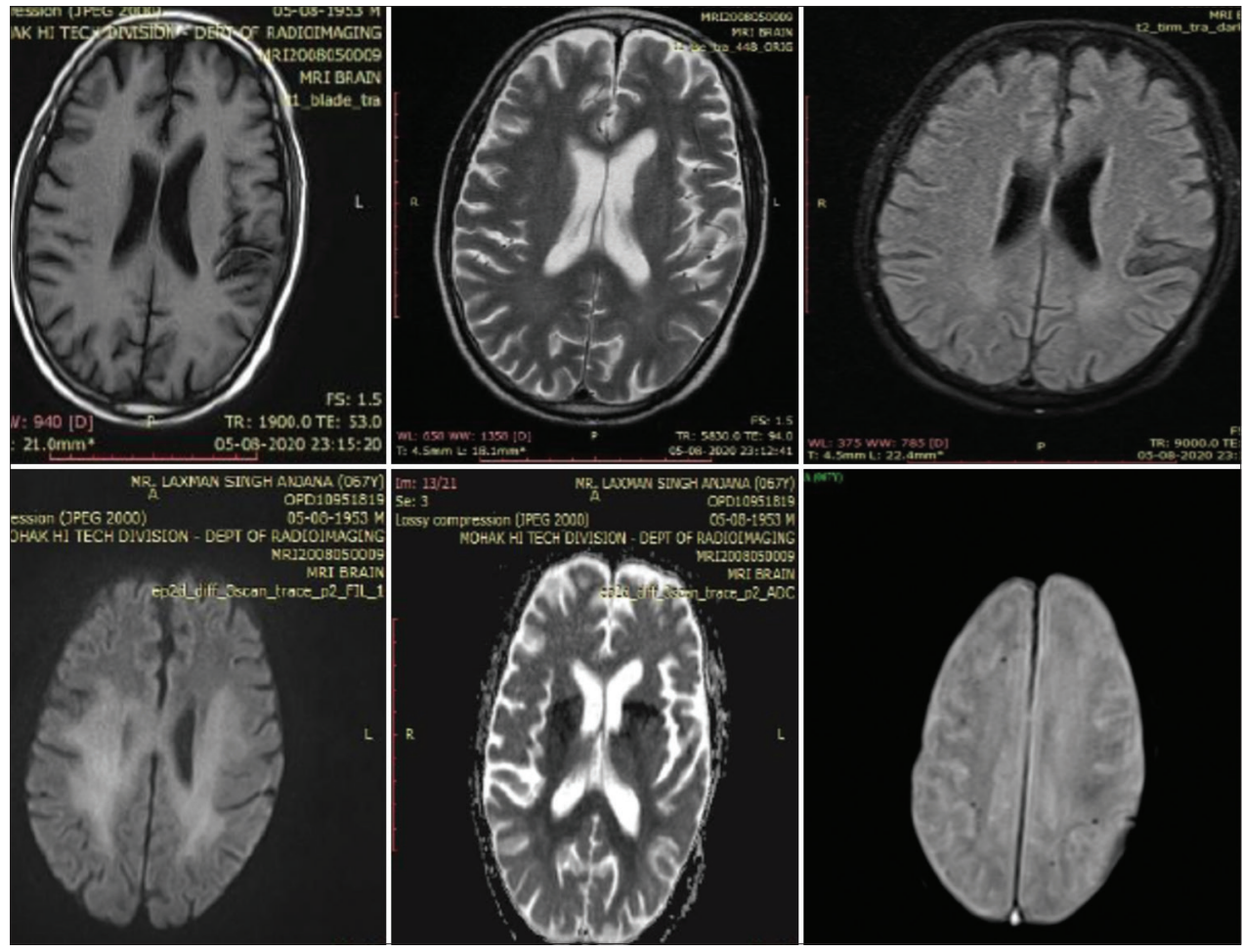

Figure 1: Bilaterally symmetrical areas of abnormal signals, appearing hyperintense on diffusion-weighted imaging, mild restricted diffusion on apparent diffusion coefficient images (mean 501) in bilateral frontoparietal - occipital subcortical and deep/periventricular white matter, bilateral hippocampi, internal capsule, and splenium of corpus callosum. Tiny foci of blooming were seen on susceptibility-weighted imaging in subcortical white matter and bilateral middle cerebellar peduncle region

\section{Access this article online}

Received - 22 December 2020

Initial Review - 07 January 2021

Accepted - 22 January 2021

DOI: $10.32677 / I J C R .2021 . v 07.101 .014$
Quick Response code

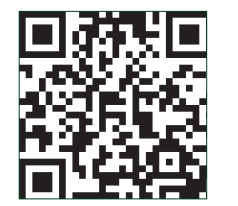

Correspondence to: Dr. Rishu Garg, Department of Neurology, Sri Aurobindo Medical College and Post Graduate Institute, Indore Ujjain Highway, Near MR-10 Crossing, Indore, Madhya Pradesh, India. E-mail: rishusgarg@gmail.com

(C) 2020 Creative Commons Attribution-NonCommercial 4.0 International License (CC BY-NC-ND 4.0). 
min, and $\mathrm{SpO}_{2}$ of $98 \%$ without oxygen support. On the $5^{\text {th }}$ day of hospitalization, he developed right hemiparesis and an episode of tonic-clonic seizure with BP of $140 / 90$, pulse rate of $98 / \mathrm{min}$, and $\mathrm{SpO}_{2}$ of $97 \%$, which remained the same for the 2 days. The patient was given an injection of fosphenytoin $20 \mathrm{mg} / \mathrm{kg}$ with a maintenance dose of the same $150 \mathrm{mg}$ I.V. 8 hourly. On the $7^{\text {th }}$ day, he had another episode of seizure and, thereafter, became unconscious with deteriorating vitals. Inotropes were started with oxygen support at $3 \mathrm{~L} / \mathrm{min}$. He remained unconscious and was put on a mechanical ventilator on day 10 in view of the poor Glasgow Coma scale and expired on the $11^{\text {th }}$ day of hospitalization. Magnetic resonance imaging (MRI) brain done on the $5^{\text {th }}$ day (development of right hemiparesis) revealed features of hemorrhagic leukoencephalitis. In our patient, MRI brain showed bilateral symmetric hyperintense signals on diffusion-weighted imaging (DWI) with mild restricted diffusion on apparent diffusion coefficient (ADC) involving bilateral frontoparietal-occipital subcortical white matter, bilateral hippocampi, internal capsule, and splenium of the corpus callosum with tiny foci of blooming on susceptibilityweighted imaging (SWI) seen in subcortical white matter and bilateral middle cerebellar peduncle region, with sparing of $U$ fibers and brain stem, these findings were compatible with acute hemorrhagic leukoencephalitis (Figure 1).

A similar case study involving brain imaging findings in 242 patients with COVID-19 was reported by Radmanesh et al. but none of the patients in that study showed a diffuse pattern of white matter involvement that is described herein. ${ }^{[2]}$ Another acute necrotizing encephalopathy in COVID-19 was reported by Poyiadji et al., but in our case, there was a lack of thalamic involvement. ${ }^{[3]}$

Acute hemorrhagic encephalitis should be recognized as a grave complication of COVID-19 infection, particularly in patients with altered mental status. Future neurohistopathological studies will elucidate the underlying pathology.

\section{REFERENCES}

1. Garg R, Jain R, Sodani A, Chouksey D, Dosi R, Athale S, et al. Neurological symptoms as initial manifestation of COVID-19 - An observational study. Ann Indian Acad Neurol 2020;23:482-6.

2. Radmanesh A, Raz E, Zan E, Derman A, Kaminetzky M. Brain Imaging use and findings in COVID-19: A single academic center experience in the epicenter of disease in the United States. AJNR Am J Neuroradiol 2020;41:1179-83.

3. Poyiadji N, Shahin G, Noujaim D, Stone M, Patel S, Griffith B. COVID-19associated acute hemorrhagic necrotizing encephalopathy: imaging features. Radiology 2020;296:E119-20.

Funding: None; Conflicts of Interest: None Stated.

How to cite this article: Jain R, Garg R, Sodani A, Chowksey D. A case of fatal acute hemorrhagic leukoencephalitis associated with severe acute respiratory syndrome-coronavirus-2 infection. Indian $\mathrm{J}$ Case Reports. 2021;7(1):42-43. 